\title{
1 Evaluation of Reproducibility in Urology Publications
}

2 Shelby Lynn Rauh, MS ${ }^{1}$, Bradley S. Johnson, MA ${ }^{1}$, Aaron Bowers BS ${ }^{1}$, Daniel Tritz, MS ${ }^{1}$,

3 Benjamin Matthew Vassar, $\mathrm{PhD}^{1}$

$4{ }^{1}$ Oklahoma State University Center for Health Sciences, Tulsa, Oklahoma.

6 Corresponding Author: Mrs. Shelby Lynn Rauh, Oklahoma State University Center for Health

7 Sciences, 1111 W 17th St., Tulsa, OK 74107, USA; email: shelby.rauh@ okstate.edu

8 Conflicts of Interest and Source of Funding: This study was funded through the 2019

9 Presidential Research Fellowship Mentor-Mentee Program at Oklahoma State University Center

10 for Health Sciences.

11

12 Keywords: Cross-Sectional, Reproducibility, Urology 
14 Take Home Message (17/40 words): Many components of transparency and reproducibility are

15 lacking in urology publications, making study replication, at best, difficult.

17 Introduction: Reproducibility is essential for the integrity of scientific research. Reproducibility

18 is measured by the ability of investigators to replicate the outcomes of an original publication by

19 using the same materials and procedures.

20 Methods: We sampled 300 publications in the field of urology for assessment of multiple

21 indicators of reproducibility, including material availability, raw data availability, analysis script

22 availability, pre-registration information, links to protocols, and whether the publication was

23 freely available to the public. Publications were also assessed for statements about conflicts of

24 interest and funding sources.

25 Results: Of the 300 sample publications, 171 contained empirical data and could be analyzed for

26 reproducibility. Of the analyzed articles, $0.58 \%$ (1/171) provided links to protocols, and none of

27 the studies provided analysis scripts. Additionally, 95.91\% (164/171) did not provide accessible

28 raw data, 97.53\% (158/162) did not provide accessible materials, and 95.32\% (163/171) did not

29 state they were pre-registered.

30 Conclusion: Current urology research does not consistently provide the components needed to

31 reproduce original studies. Collaborative efforts from investigators and journal editors are

32 needed to improve research quality, while minimizing waste and patient risk. 


\section{Introduction}

35 Reproducibility is determined by the availability of materials, raw data, analysis procedures, and

36 protocols used to conduct original research so that other researchers may replicate the findings; it

37 is crucial to establishing credible and reliable research that ultimately governs clinical practice.

38 Recent evidence suggests that up to $90 \%$ of preclinical research may not be reproducible.[1] A

39 recent survey of over 1500 researchers concurred with this assessment, with the vast majority

40 believing that biomedical research is experiencing a "reproducibility crisis".[2] Several

41 explanations have been offered for why reproducibility has become an issue, with pressure to

42 publish and the race to be the first to report new findings being among the most likely causes.[3]

43 When research is not reproducible, time and money are wasted reproducing erroneous results,

44 and patients may be exposed to ineffective or harmful therapies.[4] Concerns about

45 reproducibility span from preclinical to clinical research.

47 The field of prostate cancer research serves as an example. On the diagnostic side, in vitro

48 studies are performed on prostate biopsy samples to advance understanding of early detection

49 and diagnosis. However, widespread misuse of immunohistochemical staining exists, which

50 contributes to the lack of research reproducibility. Sfanos et al[5] argued that the ubiquitously

51 used research-grade antibodies within the biomedical research community (as opposed to clinical

52 grade used for patient diagnosis) are not routinely validated in the investigators' laboratories,

53 which may lead to variable results that cannot be reproduced in subsequent studies. On the other

54 end of the research spectrum, randomized clinical trials are conducted to evaluate the efficacy of

55 new therapeutic agents for prevention or treatment of prostate cancer. In one large-scale

56 randomized trial, Thompson et al[6] compared the effects of finasteride against placebo for 
57 prostate cancer prevention. These investigators found that finasteride prevented or delayed the

58 development of prostate cancer but also led to an increased risk of higher-grade cancer upon

59 detection. The raw data from this clinical trial were not made entirely available because of

60 patient privacy and data "messiness". Some investigators attempted to reanalyze the trial data,

61 but the results were mixed[7,8]. Since then, Baker et al[9] proposed a method to overcome

62 issues of privacy and messiness, while also fostering reproducibility of the trial outcomes.

64 Thus, when a study does not report the components needed to reproduce it, or when studies are

65 not replicated by other researchers, determining the credibility of the original findings is

66 hindered. Our study examines existing research in urology and determines how often studies

67 include markers of reproducibility and how frequently studies are replicated. This research

68 highlights the issue of reproducibility in urology, a field in which the topic has not been well

69 explored. We anticipate that our findings will prompt discussions among investigators and

70 journal editors, which may lead to improvement in the quality of research in the field.

\section{Methods}

73 We used an observational, cross-sectional study design, drawing on the methodology of

74 Hardwicke et al[10], with modifications. This study did not involve human participants and was

75 not subject to oversight or approval by an institutional review board.[11] We report our study in

76 accordance with previously published guidelines for meta-epidemiological methodology

77 research.[12] To foster transparency and reproducibility, we have uploaded our protocol, data

78 extraction form, and other materials for public viewing on the Open Science Framework (OSF;

79 https://osf.io/n4yh5/). 


\section{Journal Selection}

82 We used the National Library of Medicine (NLM) catalog to search for all relevant journals,

83 using the subject terms tag Urology[ST]. The search was performed on 30 May 2019. The

84 inclusion criteria required journals to have full-text publications in English and be MEDLINE

85 indexed. The list of journals in the NLM catalog fitting the inclusion criteria were then extracted

86 using the electronic International Standard Serial Number (ISSN) or the linking ISSN when the

87 electronic ISSN was unavailable. PubMed was searched with the list of ISSNs to identify all

88 articles published from 1 January 2014 to 31 December 2018. We randomly sampled 300

89 publications that met the inclusion criteria (https://osf.io/csf5t/).

91 Data Extraction Training

92 The two investigators responsible for data extraction (S.R. and B.J.) underwent a full day of

93 training to ensure adequate interrater reliability. The training included an in-person session to

94 review the project study design, protocol, data extraction form, and examples of where

95 information may be contained using two example publications. The investigators were then

96 given three example publications from which to extract data in a blinded fashion. Afterward, the

97 pair reconciled differences in their results. This training session was recorded from the

98 presenter's point of view (D.T.) and listed online for reference (https://osf.io/tf7nw/). As a final

99 training exercise, investigators extracted data from the first 10 publications of the full sample and

100 then met to reconcile any differences in the data before proceeding to extraction of the remaining

101290 publications. 
104 Data extraction on the remaining 290 publications was conducted in a duplicate, blinded fashion.

105 A final consensus meeting was held with both investigators to resolve disagreements. A third

106 investigator (D.T.) was available for adjudication but was not needed. Data were extracted using

107 a pilot-tested Google form based on Hardwicke et al, with modifications.[10] This form

108 contained information necessary for a study to be reproducible, such as the availability of

109 materials, data, protocols, or analysis scripts (https://osf.io/3nfa5/). The data extracted varied

110 based on the study design, with studies having no empirical data being excluded (e.g., editorials,

111 commentaries [without reanalysis], simulations, news, reviews, and poems) (Table 1). The form

112 also included the 5-year impact factor and that of the most recent year available and expanded

113 the study design options to include cohort studies, case series, secondary analyses, chart reviews,

114 and cross-sectional studies. Funding options were also expanded to include university, hospital,

115 public, private/industry, non-profit, or mixed funding.

117 Evaluation of Open Access Status

118 We evaluated all 300 publications to determine whether they were freely available online

119 through open access. We searched Open Access Button (openaccessbutton.org) with publication

120 titles and DOI numbers. This tool actively searches for the full-text online. If it could not find a

121 publication, two of us (S.R. and B.J.) searched Google Scholar and PubMed to determine if the

122 full text was available via open access on the journal website.

123

124 Evaluation of Replication and Whether Publications Were Included in Research Synthesis 
125 For empirical studies, excluding meta-analysis and commentary with analysis, we searched the

126 Web of Science to determine whether the publication was cited in a replication study, meta-

127 analysis, or systematic review. The Web of Science additionally lists information important for

128 our study, such as the country of journal publication, 5-year impact factor (when available), and

129 most recent impact factor.

130

$131 \quad$ Statistical Analysis

132 We report descriptive statistics for each of our findings with $95 \%$ confidence intervals (95\% CIs)

133 using analysis functions within Microsoft Excel.

135 Results

136 Included Sample and Characteristics

137 Our inclusion criteria resulted in 42,422 articles from 46 urology journals found in the NLM

138 catalog. Of the articles meeting the inclusion criteria, 300 articles were randomly chosen for

139 analysis. Six articles were not analyzed because we did not have access to the text. The

140 remaining 294 articles were assessed to determine the 5-year impact factor of their

141 corresponding journals. Twenty of the 294 articles came from journals without 5-year impact

142 factors. Thus, journals of the 274 studies reported a median of 2.466 as their 5-year impact factor

143 with an interquartile range of 1.898 to 4.925. In addition, a full assessment of the original 300

144 articles revealed that 88 (29.33\%) were accessible through Open Access Button or other means.

145 Over half of our included studies $(163 / 294,55.44 \%)$ provided a statement revealing that their

146 study was without a conflict of interest. However, 95 (32.31\%) of our included studies did not

147 provide any type of conflict of interest statement. Nearly two-thirds of our studies $(185,62.93 \%)$ 
148 did not state if or from where they received funding. Among the 109 studies that provided a

149 statement, most did not receive funding $(31,28.44 \%)$. Of the 78 studies that did receive funding,

150 most obtained it through public entities $(23,29.49 \%)$. Other characteristics of our included

151 studies can be found in Table 2 and Supplementary Table 1.

\section{Characteristics Associated with Reproducibility}

154 The only studies that were assessed for reproducibility were those that had empirical data. Thus,

155115 articles without empirical data were excluded from the initial 294 studies. We also excluded

156 eight case studies and case series because such studies cannot be reproduced. We therefore

157 assessed a total of 171 studies for reproducibility. Of these studies, $163(95.32 \%)$ did not provide

158 a pre-registration statement. Among the 8 studies that provided a pre-registration statement, 4

159 had accessible links to the pre-registration. Nearly all analyzed studies omitted a data availability

160 statement $(162 / 171,94.74 \%)$. Of the 9 studies that provided a data statement, 2 claimed that their

161 data was not available. None of the 7 studies that claimed their data were available provided

162 enough raw data for the study to be reproduced. Similarly, $156(96.30 \%)$ of 162 analyzed studies

163 (excluding meta-analyses) did not provide a material availability statement. Six studies provided

164 a material availability statement; five of these publications included a statement that materials

165 were available, but only four provided working links to the materials. Only one of the 171

166 studies included a full protocol in the publication, and none of the 171 studies provided an

167 analysis script availability statement. More characteristics associated with reproducibility are

168 presented in Supplementary Table 1.

\section{Discussion}


171 Our study revealed concerning findings regarding the reproducibility of research in urology

172 literature. Only nine studies made statements regarding the availability of data, and only seven of

173 those actually made their data available. Fewer than half of the studies in our sample were

174 available through Open Access Button, and detailed protocols and pre-registration were rare.

175 One trial in our sample was claimed to be a replication of a previous study, but even this

176 publication failed to include any of the reproducibility markers that we assessed. These findings

177 are similar to those of Hardwicke et al[10] for a survey of reproducibility in social sciences.

179 Our study revealed that only one study contained a link to protocols, while no studies provided

180 analysis scripts and only six provided materials statements. These elements are the three most

181 important ones in reproducing a study. Protocols provide details about how each step of the study

182 was performed, to an extent much deeper than would be relevant to the average person reading

183 the methods section.[13,14] Similarly, analysis scripts are crucial for re-creating the original

184 analysis in a stepwise manner.[15] Materials include anything that was necessary for the study to

185 be performed, including forms, questionnaires, devices, software programs, and more.[16] Some

186 investigators have posited that freely providing these elements invites plagiarism of study design,

187 a major concern with the pressure on researchers to publish while limiting time and funding.[17]

188 Chan et al[18] have suggested placing protocols in a lockbox and making them available upon

189 data release to protect intellectual property, while maintaining reproducible research. At the very

190 least, authors should state in their articles that these crucial elements of reproducibility are

191 available upon reasonable request. 
193 Pre-registration is one of the best ways to increase transparency and reproducibility in research,

194 yet only eight studies from our sample were pre-registered. Pre-registration of trials encourages

195 transparency in research by outlining the intended outcomes, interventions, protocols, and

196 methods of analysis before the study is underway.[19] When trials are not pre-registered,

197 investigators have the freedom to manipulate data to obtain significance (P-hacking)[20],

198 hypothesize after results are known (HARKing)[21], switch primary outcomes[22], or deviate

199 from a priori protocols.[23] Several researchers, including Nosek et al[24] have called for

200 widespread adoption of pre-registration, citing its value in increasing transparency, rigor, and

201 reproducibility. Early results of pre-registration are positive, with pre-registered studies

202 exhibiting a significant increase in null findings.[25] The OSF hosts pre-registration free of

203 charge and also provides pre-registration templates and instructional guides.[26,27] High-impact

204 journals could require pre-registration for any study to be considered for publication, which

205 would encourage authors to take the necessary steps to increase the chance of having their

206 research published in a respected journal.

208 Data availability is another area in which urology research falls short. Some journals, including

209 European Urology, have begun to require that authors' manuscripts include a description of how

210 readers can access underlying data, while other journals mandate the inclusion of study

211 protocols, analysis scripts, and any other element needed to replicate the original study.[28,29]

212 Beginning in 2019, the International Committee of Medical Journal Editors (ICMJE) mandated

213 data sharing statements by all prospective clinical trials submitted for publication to an ICMJE

214 member journal.[30] Showing that such policies can be successful, PLoS One, another journal

215 requiring data availability, reported that $20 \%$ of studies published in the journal hosted their data 
216 on a third-party website, $60 \%$ provided their data in a supplement, and the remaining $20 \%$ made

217 their data available upon reasonable request.[31] These initiatives are steps in the right direction,

218 and we propose a few more possibilities for improving reproducibility in urology research.

220 The Repeat framework was designed by McIntosh et al[32] to improve reproducibility in

221 research. This easy-to-use checklist can be adapted for most studies. Additionally, the OSF

222 developed the Transparency and Openness Promotion (TOP) Guidelines, which provide eight

223 modular standards designed to increase transparency, disclosure, openness, and

224 collaboration.[33] The EQUATOR network has set out to improve research reporting and

225 manuscript writing through the use of reporting guidelines.[34,35] These guidelines, available

226 for nearly every type of study, ensure that manuscripts are written in a transparent way,

227 encouraging reproducibility and accurate reporting of findings.[12] Some journals have begun to

228 require the use of reporting guidelines in the studies they publish.[36-38]

230 Our study has both strengths and limitations. Regarding strengths, we applied double data

231 extraction procedures, which is considered a best practice methodology by the systematic review

232 community and is recommended in the Cochrane Handbook for Systematic Reviews of

233 Interventions.[44] To foster study reproducibility and transparency, we have made all relevant

234 study materials publicly available on OSF. Concerning limitations, our study is cross-sectional in

235 nature, including only PubMed-indexed journals that were published in English during a finite

236 time period. Thus, our results should be interpreted in light of these considerations. Additionally,

237 many replication studies are not published because they are never submitted for publication.[2]

238 In recent years, some organizations, including Elsevier, have encouraged the submission and 
239 publication of replication studies, but they are not yet common in biomedical literature.[45] We

240 did not attempt to contact authors for data availability, analysis scripts, protocols, or any of the

241 other markers of reproducibility. While we may have found these things to be readily available,

242 it is more likely that we would have run up against the familiar issues of low response rate and

243 limited cooperation.[46,47]

244

\section{Conclusion}

246 Current urology research does not consistently provide the components needed to reproduce

247 original studies. Collaborative efforts from investigators and journal editors are needed to

248 improve research quality, while minimizing waste and patient risk. 


\section{References}

252

1. Begley CG, Glenn Begley C, Ioannidis JPA. Reproducibility in Science [Internet]. Vol. 116, Circulation Research. 2015. p. 116-26. Available from: http://dx.doi.org/10.1161/circresaha.114.303819

2. Baker M. Is there a reproducibility crisis? A Nature survey lifts the lid on how researchers view the'crisis rocking science and what they think will help. Nature. 2016;533(7604):452-5.

3. Eisner DA. Reproducibility of science: Fraud, impact factors and carelessness. J Mol Cell Cardiol. 2018 Jan;114:364-8.

4. Loscalzo J. Irreproducible experimental results: causes, (mis)interpretations, and consequences. Circulation. 2012 Mar 13;125(10):1211-4.

5. Sfanos KS, Yegnasubramanian S, Nelson WG, Lotan TL, Kulac I, Hicks JL, et al. If this is true, what does it imply? How end-user antibody validation facilitates insights into biology and disease. Asian J Urol. 2019 Jan;6(1):10-25.

6. Thompson IM, Goodman PJ, Tangen CM, Lucia MS, Miller GJ, Ford LG, et al. The influence of finasteride on the development of prostate cancer. N Engl J Med. 2003 Jul 17;349(3):215-24.

7. Redman MW, Tangen CM, Goodman PJ, Lucia MS, Coltman CA Jr, Thompson IM. Finasteride does not increase the risk of high-grade prostate cancer: a bias-adjusted modeling approach. Cancer Prev Res . 2008 Aug;1(3):174-81.

8. Shepherd BE, Redman MW, Ankerst DP. Does Finasteride Affect the Severity of Prostate Cancer? A Causal Sensitivity Analysis. J Am Stat Assoc. 2008 Dec 1;103(484):1392-404.

9. Baker SG, Darke AK, Pinsky P, Parnes HL, Kramer BS. Transparency and reproducibility in data analysis: the Prostate Cancer Prevention Trial. Biostatistics. 2010 Jul;11(3):413-8.

10. Hardwicke TE, Wallach JD, Kidwell M, Ioannidis J. An empirical assessment of transparency and reproducibility-related research practices in the social sciences (2014-2017) [Internet]. 2019. Available from: http://dx.doi.org/10.31222/osf.io/6uhg5

11. eCFR — Code of Federal Regulations [Internet]. [cited 2019 Jun 27]. Available from: https://www.ecfr.gov/cgibin/retrieveECFR?gp=\&SID=83cd09e1 c0f5c6937cd9d7513160fc3f \&pitd=20180719\&n=pt45.1.46\& $\mathrm{r}=$ PART \& $\mathrm{ty}=\mathrm{HTML}$

12. Murad MH, Wang Z. Guidelines for reporting meta-epidemiological methodology research. Evid Based Med. 2017 Aug;22(4):139-42.

13. Jirge PR. Preparing and Publishing a Scientific Manuscript. J Hum Reprod Sci. 2017 Jan;10(1):3-9.

14. Jundi AA, Al Jundi A. Protocol Writing in Clinical Research [Internet]. JOURNAL OF CLINICAL AND DIAGNOSTIC RESEARCH. 2016. Available from: http://dx.doi.org/10.7860/jcdr/2016/21426.8865

15. Piccolo SR, Frampton MB. Tools and techniques for computational reproducibility. Gigascience. 2016 Jul 11;5(1):30. 
16. Reddy P, Bhadauria U. Integral elements of a research protocol [Internet]. Vol. 31, Journal of Indian Academy of Oral Medicine and Radiology. 2019. p. 167. Available from: http://dx.doi.org/10.4103/jiaomr.jiaomr_220_18

17. Ross S, Magee L, Walker M, Wood S. Protecting intellectual property associated with Canadian academic clinical trials--approaches and impact. Trials. 2012 Dec 27;13:243.

18. Chan A-W, Hróbjartsson A. Promoting public access to clinical trial protocols: challenges and recommendations. Trials. 2018 Feb 17;19(1):116.

19. Mistler S. Planning your analyses: Advice for avoiding analysis problems in your research. Psychological Science Agenda. 2012;26(11).

20. Simmons JP, Nelson LD, Simonsohn U. False-positive psychology: undisclosed flexibility in data collection and analysis allows presenting anything as significant. Psychol Sci. 2011 Nov;22(11):1359-66.

21. Kerr NL. HARKing: hypothesizing after the results are known. Pers Soc Psychol Rev. 1998;2(3):196-217.

22. Howard B, Scott JT, Blubaugh M, Roepke B, Scheckel C, Vassar M. Systematic review: Outcome reporting bias is a problem in high impact factor neurology journals. PLoS One. $2017 \mathrm{Jul}$ 20;12(7):e0180986.

23. Ghooi RB, Bhosale N, Wadhwani R, Divate P, Divate U. Assessment and classification of protocol deviations. Perspect Clin Res. 2016 Jul;7(3):132-6.

24. Nosek BA, Ebersole CR, DeHaven AC, Mellor DT. The preregistration revolution. Proc Natl Acad Sci U S A. 2018 Mar 13;115(11):2600-6.

25. Allen C, Mehler DMA. Open science challenges, benefits and tips in early career and beyond. PLoS Biol. 2019 May;17(5):e3000246.

\section{OSF [Internet]. [cited 2019 Jul 12]. Available from: https://osf.io/}

27. Templates of OSF Registration Forms. 2016 Oct 31 [cited 2019 Jul 18]; Available from: https://osf.io/zab38/wiki/home/

28. Myers MG Jr, Diabetes Editorial Team. Diabetes Takes New Steps to Increase Transparency and Reproducibility. Diabetes. 2019 Apr;68(4):681-2.

29. Guide for Authors: European Urology.

30. Taichman DB, Sahni P, Pinborg A, Peiperl L, Laine C, James A, et al. Data Sharing Statements for Clinical Trials - A Requirement of the International Committee of Medical Journal Editors [Internet]. Vol. 376, New England Journal of Medicine. 2017. p. 2277-9. Available from: http://dx.doi.org/10.1056/nejme1705439

31. 0000-0003-1953-, 0000-0002-7378-. Making Progress Toward Open Data: Reflections on Data Sharing at PLOS ONE | EveryONE: The PLOS ONE blog [Internet]. EveryONE. 2017 [cited 2019 Jul 16]. Available from: https://blogs.plos.org/everyone/2017/05/08/making-progress-toward-opendata/ 
32. McIntosh LD, Juehne A, Vitale CRH, Liu X, Alcoser R, Lukas JC, et al. Repeat: a framework to assess empirical reproducibility in biomedical research. BMC Med Res Methodol. 2017 Sep 18;17(1):143.

33. Nosek BA, Alter G, Banks GC, Borsboom D, Bowman SD, Breckler SJ, et al. Transparency and Openness Promotion (TOP) Guidelines [Internet]. 2016. Available from: http://dx.doi.org/10.1126/science.aab2374

34. Carpenter CR, Meisel ZF. Overcoming the Tower of Babel in Medical Science by Finding the "EQUATOR": Research Reporting Guidelines. Acad Emerg Med [Internet]. 2017 May 11; Available from: http://dx.doi.org/10.1111/acem.13225

35. The EQUATOR Network | Enhancing the QUAlity and Transparency Of Health Research [Internet]. [cited 2017 Jun 16]. Available from: http://www.equator-network.org/

36. Jorski A, Scott J, Heavener T, Vassar M. Reporting guideline and clinical trial registration requirements in gastroenterology and hepatology journals. Int J Evid Based Healthc. 2018 Jun;16(2):119-27.

37. Sims MT, Bowers AM, Fernan JM, Dormire KD, Herrington JM, Vassar M. Trial registration and adherence to reporting guidelines in cardiovascular journals. Heart. 2018 May;104(9):753-9.

38. Sims MT, Henning NM, Wayant CC, Vassar M. Do emergency medicine journals promote trial registration and adherence to reporting guidelines? A survey of "Instructions for Authors." Scand J Trauma Resusc Emerg Med. 2016 Nov 24;24(1):137.

39. Wan J, Cain MP, Tanaka S, Nelson C. Conflict of Interest, Self-Reporting and Our Profession. J Urol. 2019 Apr;201(4):678-9.

40. Carlisle A, Bowers A, Wayant C, Meyer C, Vassar M. Financial Conflicts of Interest Among Authors of Urology Clinical Practice Guidelines. Eur Urol. 2018 Sep;74(3):348-54.

41. Jimbo M, Granberg CF, Osumah TS, Bandari J, Cannon GM, Routh JC, et al. Discrepancies in SelfReported and Actual Conflicts of Interest for Robotic Pediatric Urological Surgery. J Urol. 2019 Feb;201(2):393-9.

42. Lotbiniere-Bassett MP de, de Lotbiniere-Bassett MP, Riva-Cambrin J, McDonald PJ. Conflict of interest policies and disclosure requirements in neurosurgical journals [Internet]. Vol. 131, Journal of Neurosurgery. 2019. p. 264-70. Available from: http://dx.doi.org/10.3171/2018.4.jns172751

43. Shawwa K, Kallas R, Koujanian S, Agarwal A, Neumann I, Alexander P, et al. Requirements of Clinical Journals for Authors' Disclosure of Financial and Non-Financial Conflicts of Interest: A Cross Sectional Study [Internet]. Vol. 11, PLOS ONE. 2016. p. e0152301. Available from: http://dx.doi.org/10.1371/journal.pone.0152301

44. Green S, Higgins J, Alderson P, Clarke M, Mulrow CD, Oxman AD, et al. Cochrane handbook for systematic reviews of interventions. West Sussex, England: John Wiley \& Sons Ltd [Internet]. 2008; Available from: http://librariesbegan.info/cochrane-handbook-for-systematic-reviews-ofinterventions-to-spread-book-julian-p-t-higgins-sally-green-cochrane-collaboration.pdf

45. Elsevier, Hylke Koers Phd And. New article type verifies experimental reproducibility [Internet]. Elsevier Connect. 2016 [cited 2019 Jul 17]. Available from: https://www.elsevier.com/connect/new- 
article-type-verifies-experimental-reproducibility

46. Vines TH, Albert AYK, Andrew RL, Débarre F, Bock DG, Franklin MT, et al. The availability of research data declines rapidly with article age. Curr Biol. 2014 Jan 6;24(1):94-7.

47. Hardwicke TE, Ioannidis JPA. Populating the Data Ark: An attempt to retrieve, preserve, and liberate data from the most highly-cited psychology and psychiatry articles. PLoS One. 2018 Aug 2;13(8):e0201856. 
383 Figure 1: Flow Diagram of Included and Excluded Studies for the Reproducibility Analysis

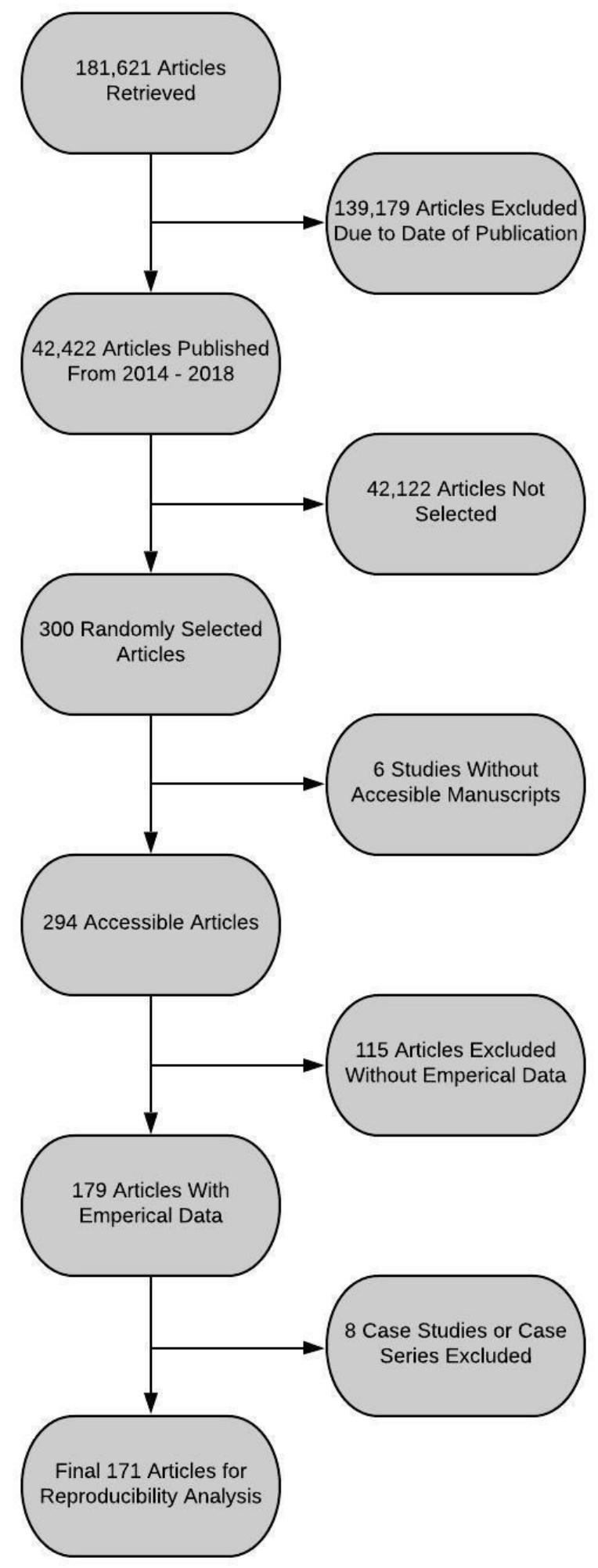


Table 1: Types of Characteristics Associated with Reproducibility. Sample Sizes (N) depend on study type. Protocol about our measured characteristics is found online. (https://osf.io/x24n3/)

\begin{tabular}{|c|c|c|}
\hline \multicolumn{2}{|r|}{ Reproducibility Markers } & $\begin{array}{l}\text { The Importance of Each Marker in Regards } \\
\text { with Transparency and Reproducibility. }\end{array}$ \\
\hline \multicolumn{3}{|l|}{ Accessibility } \\
\hline All $(\mathrm{N}=300)$ & $\begin{array}{l}\text { Article accessibility (Is the article } \\
\text { available to the public without a } \\
\text { paywall?) }\end{array}$ & $\begin{array}{l}\text { Accessible research allows for a larger } \\
\text { audience to assess and replicate a study's } \\
\text { findings. }\end{array}$ \\
\hline \multicolumn{3}{|l|}{ Funding } \\
\hline $\begin{array}{l}\text { Included } \\
\text { studies } \\
(\mathrm{N}=294)\end{array}$ & $\begin{array}{l}\text { Funding statement (Do authors } \\
\text { provide a statement to describe if or } \\
\text { how the study was funded?) }\end{array}$ & $\begin{array}{l}\text { Including a funding statement provides } \\
\text { greater transparency to readers. This increased } \\
\text { transparency reveals any signs of bias or } \\
\text { influence in the study's methodology. }\end{array}$ \\
\hline \multicolumn{3}{|c|}{ Conflict of Interest } \\
\hline $\begin{array}{l}\text { Included } \\
\text { studies } \\
(\mathrm{N}=294)\end{array}$ & $\begin{array}{l}\text { Conflict of interest statement (Do } \\
\text { the authors reveal any conflicts of } \\
\text { interest in their manuscript?) }\end{array}$ & $\begin{array}{l}\text { Conflict of interest statements give the } \\
\text { authors a chance to be transparent about } \\
\text { relationships with entities that may try to } \\
\text { influence a study's findings. }\end{array}$ \\
\hline \multicolumn{3}{|c|}{ Publication Citations } \\
\hline $\begin{array}{l}\text { Empirical } \\
\text { studies } \dagger \\
(\mathrm{N}=171)\end{array}$ & $\begin{array}{l}\text { Systematic review/meta-analysis } \\
\text { citations (Has the study been cited } \\
\text { by data synthesis study designs such } \\
\text { as systematic reviews or meta- } \\
\text { analyses?) }\end{array}$ & $\begin{array}{l}\text { Systematic reviews and meta-analyses } \\
\text { synthesize information in studies that may } \\
\text { have been replicated. The synthesis of } \\
\text { information reveals a more complete answer } \\
\text { to the question being investigated. }\end{array}$ \\
\hline \multicolumn{3}{|c|}{ Analysis Scripts } \\
\hline \multirow{3}{*}{$\begin{array}{l}\text { Empirical } \\
\text { studies } \$ \\
(\mathrm{~N}=171)\end{array}$} & $\begin{array}{l}\text { Availability statement (Is there a } \\
\text { statement in the manuscript } \\
\text { describing the accessibility of the } \\
\text { analysis script?) }\end{array}$ & \multirow{3}{*}{$\begin{array}{l}\text { Having the analysis script allows raw data to } \\
\text { be analyzed exactly as the authors did in the } \\
\text { original study, allowing others to replicate the } \\
\text { data analysis correctly. }\end{array}$} \\
\hline & $\begin{array}{l}\text { Location of Analysis Script (Where } \\
\text { can the analysis script be found? ie. } \\
\text { supplementary material) }\end{array}$ & \\
\hline & $\begin{array}{l}\text { Accessibility (Can a reader access } \\
\text { the analysis script through the } \\
\text { manuscript online or through other } \\
\text { methods?) }\end{array}$ & \\
\hline
\end{tabular}




\begin{tabular}{|c|c|c|}
\hline \multicolumn{3}{|l|}{ Materials } \\
\hline \multirow{3}{*}{$\begin{array}{l}\text { Empirical } \\
\text { studiesII } \\
(\mathrm{N}=162)\end{array}$} & $\begin{array}{l}\text { Availability statement (Is there a } \\
\text { statement in the manuscript } \\
\text { describing the accessibility of } \\
\text { additional materials to the study?) }\end{array}$ & \multirow{3}{*}{$\begin{array}{l}\text { Additional materials allows readers to learn } \\
\text { what is needed to reproduce the study, } \\
\text { enabling the study to be replicated. }\end{array}$} \\
\hline & $\begin{array}{l}\text { Location of additional materials } \\
\text { (Where can the additional material } \\
\text { be found? ie. supplementary } \\
\text { materials?) }\end{array}$ & \\
\hline & $\begin{array}{l}\text { Accessibility (Can a reader access } \\
\text { additional material through the } \\
\text { manuscript online or through other } \\
\text { methods?) }\end{array}$ & \\
\hline \multicolumn{3}{|c|}{ Pre-registration } \\
\hline \multirow{4}{*}{$\begin{array}{l}\text { Empirical } \\
\text { studies } \neq \\
(\mathrm{N}=138)\end{array}$} & $\begin{array}{l}\text { Availability statement (Is there a } \\
\text { statement in the manuscript } \\
\text { describing whether the study was } \\
\text { pre-registered or not?) }\end{array}$ & \multirow{4}{*}{$\begin{array}{l}\text { Pre-registering a study prevents any } \\
\text { tampering of the study design throughout } \\
\text { implementation of the study, increasing the } \\
\text { reliability of the study. Also, pre-registration } \\
\text { can provide components that may aid in } \\
\text { replicating a study. }\end{array}$} \\
\hline & $\begin{array}{l}\text { Location of registration(Where was } \\
\text { the study registered?) }\end{array}$ & \\
\hline & $\begin{array}{l}\text { Accessibility of the registration (Is } \\
\text { the registration accessible?) }\end{array}$ & \\
\hline & $\begin{array}{l}\text { Components included in registration } \\
\text { (What components of the study } \\
\text { were found in the registration?) }\end{array}$ & \\
\hline \multicolumn{3}{|l|}{ Protocols } \\
\hline \multirow{2}{*}{$\begin{array}{c}\text { Empirical } \\
\text { studies } \neq \\
(\mathrm{N}=171)\end{array}$} & $\begin{array}{l}\text { Availability statement (Is there a } \\
\text { statement in the manuscript } \\
\text { describing whether the study } \\
\text { protocol was available or not?) }\end{array}$ & \multirow{2}{*}{$\begin{array}{l}\text { Access to a detailed protocol allows others to } \\
\text { know what, where, why, and how the study } \\
\text { was performed, aiding others in the } \\
\text { replication of the original study. }\end{array}$} \\
\hline & $\begin{array}{l}\text { Components (What components of } \\
\text { the study were found in the } \\
\text { protocol?) }\end{array}$ & \\
\hline \multicolumn{3}{|l|}{ Raw Data } \\
\hline \multirow{2}{*}{$\begin{array}{l}\text { Empirical } \\
\text { studies } \neq \\
(\mathrm{N}=171)\end{array}$} & $\begin{array}{l}\text { Availability statement (Is there a } \\
\text { statement in the manuscript } \\
\text { describing the accessibility of raw } \\
\text { data from the study?) }\end{array}$ & \multirow{2}{*}{$\begin{array}{l}\text { Raw data provides insight into the author's } \\
\text { thoughts and actions throughout } \\
\text { implementation of the study, aiding others in } \\
\text { replication of the original study. Additionally, } \\
\text { raw data provides transparency to what is } \\
\text { presented in the study's findings. }\end{array}$} \\
\hline & $\begin{array}{l}\text { Method of availability (Where can } \\
\text { the raw data be found? ie. } \\
\text { supplementary materials?) }\end{array}$ & \\
\hline
\end{tabular}


Accessibility (Can a reader access raw data through the manuscript online or through other methods?)

Components (Are all the components of raw data that is needed to replicate the study available?)

Clarity (Is the raw data understandable?)

$\dagger$ Empirical studies are studies with empirical data such as: clinical trial, cohort, case series, case reports, case-control, secondary analysis, chart review, commentaries (with data analysis), laboratory, and cross-sectional designs.

\$ Empirical studies that are case reports, case series, or studies without World of Science access were excluded from the reproducibility analysis (materials, data, protocol, and registration were excluded ) as recommended by Hardwick et al[10].

II Empirical studies that are either case reports, case series, commentaries with analysis, metaanalyses, or systematic reviews were excluded as they are not expected to provide additional materials. 


\begin{tabular}{|c|c|c|}
\hline \multicolumn{3}{|c|}{ Table 2: Characteristics of Included Publications } \\
\hline \multicolumn{2}{|c|}{ Characteristics } & Variables \\
\hline & & $\mathbf{N}(\%)$ \\
\hline \multirow{8}{*}{$\begin{array}{l}\text { Funding } \\
(\mathrm{N}=294)\end{array}$} & University & $4(1.36 \%)$ \\
\hline & Hospital & $1(0.34 \%)$ \\
\hline & Public & $23(7.82 \%)$ \\
\hline & Private/Industry & $20(6.80 \%)$ \\
\hline & Non-Profit & $2(0.68 \%)$ \\
\hline & Mixed & $28(9.52 \%)$ \\
\hline & No Statement Listed & $185(62.93 \%)$ \\
\hline & No Funding Received & $31(10.54 \%)$ \\
\hline \multirow{11}{*}{$\begin{array}{l}\text { Type of Study } \\
\qquad(\mathrm{N}=294)\end{array}$} & No Empirical Data & $115(39.12 \%)$ \\
\hline & Meta-Analysis & $9(3.06 \%)$ \\
\hline & Chart Review & $10(0.34 \%)$ \\
\hline & Clinical Trial & $22(7.48 \%)$ \\
\hline & Case Study & $6(2.04 \%)$ \\
\hline & Case Series & $2(0.68 \%)$ \\
\hline & Cohort & $94(31.97 \%)$ \\
\hline & Case Control & $2(0.68 \%)$ \\
\hline & Survey & $8(2.72 \%)$ \\
\hline & Laboratory & $17(5.78 \%)$ \\
\hline & Other & $9(3.06 \%)$ \\
\hline \multirow{4}{*}{$\begin{array}{c}5 \text { Year Impact } \\
\text { Factor } \\
(\mathrm{N}=274)\end{array}$} & Median & 2.466 \\
\hline & 1st Quartile & 1.898 \\
\hline & 3rd Quartile & 4.925 \\
\hline & Interquartile Range & $1.898-4.925$ \\
\hline
\end{tabular}




\begin{tabular}{|c|c|c|c|}
\hline \multicolumn{4}{|c|}{$\begin{array}{l}\text { Supplemental 1: Additional Characteristics of Reproducibility in } \\
\text { Urology Studies }\end{array}$} \\
\hline \multicolumn{2}{|l|}{ Characteristics } & \multicolumn{2}{|l|}{ Variables } \\
\hline & & $\mathbf{N}(\%)$ & $95 \% \mathrm{CI}$ \\
\hline \multirow{3}{*}{$\begin{array}{l}\text { Conflict of } \\
\text { Interest } \\
\text { Statement } \\
(\mathbf{N}=\mathbf{2 9 4})\end{array}$} & $\begin{array}{l}\text { Statement, one or more conflicts of } \\
\text { interest }\end{array}$ & $36(12.24 \%)$ & $8.54-15.95$ \\
\hline & Statement. no conflict of interest & $163(55.44 \%)$ & $49.82-61.07$ \\
\hline & No conflict of interest statement & $95(32.31 \%)$ & $27.02-37.61$ \\
\hline \multirow{3}{*}{$\begin{array}{l}\text { Data } \\
\text { Availability } \\
(\mathrm{N}=171)\end{array}$} & Statement, some data are available & $7(4.09 \%)$ & $1.85-6.34$ \\
\hline & Statement, data are not available & $2(1.17 \%)$ & $0-2.39$ \\
\hline & No data availability statement & $162(94.74 \%)$ & $92.21-97.26$ \\
\hline \multirow{3}{*}{$\begin{array}{l}\text { Material } \\
\text { Availability } \\
(\mathrm{N}=162)\end{array}$} & $\begin{array}{l}\text { Statement, some materials are } \\
\text { available }\end{array}$ & $5(3.09 \%)$ & $1.13-5.04$ \\
\hline & $\begin{array}{l}\text { Statement, materials are not } \\
\text { available }\end{array}$ & $1(0.62 \%)$ & $0-1.50$ \\
\hline & No materials availability statement & $156(96.30 \%)$ & $94.16-98.43$ \\
\hline \multirow{2}{*}{$\begin{array}{l}\text { Protocol } \\
\text { Availability } \\
(\mathrm{N}=171)\end{array}$} & Full Protocol & $1(0.58 \%)$ & $0-1.45$ \\
\hline & No Protocol & $170(99.42 \%)$ & $98.55-100$ \\
\hline \multirow{3}{*}{$\begin{array}{l}\text { Analysis Scripts } \\
(\mathrm{N}=171)\end{array}$} & $\begin{array}{l}\text { Statement, some analysis scripts } \\
\text { area vailable }\end{array}$ & $0(0 \%)$ & - \\
\hline & $\begin{array}{l}\text { Statement, analysis scripts are not } \\
\text { available }\end{array}$ & $0(0 \%)$ & - \\
\hline & $\begin{array}{l}\text { No analysis script availability } \\
\text { statement }\end{array}$ & $171(100 \%)$ & - \\
\hline \multirow{2}{*}{$\begin{array}{l}\text { Replication } \\
\text { Studies } \\
(\mathrm{N}=171)\end{array}$} & Novel study & $170(99.42 \%)$ & $98.55-100$ \\
\hline & Replication & $1(0.58 \%)$ & $0-1.45$ \\
\hline $\begin{array}{l}\text { Open Access } \\
(\mathrm{N}=300)\end{array}$ & $\begin{array}{l}\text { Yes - found via Open Access } \\
\text { Button }\end{array}$ & $87(29.00 \%)$ & $23.87-34.13$ \\
\hline
\end{tabular}




\begin{tabular}{|c|c|c|c|}
\hline & Yes - found article via other means & $1(0.33 \%)$ & $0-0.99$ \\
\hline & Could not access through paywall & $212(70.67 \%)$ & $65.51-75.82$ \\
\hline \multirow{3}{*}{\begin{tabular}{|l|} 
Cited in \\
Systematic \\
Review/ \\
Meta-Analysis (a) \\
$(\mathrm{N}=169)$
\end{tabular}} & No Citations & $140(82.84 \%)$ & $78.57-87.11$ \\
\hline & A Single Citation & $20(11.83 \%)$ & $8.18-15.49$ \\
\hline & One to Five Citations & $9(5.33 \%)$ & $2.78-7.87$ \\
\hline \multicolumn{4}{|c|}{$\begin{array}{l}\text { Abbreviations: CI, Confidence Interval. a - No studies were explicitly excluded from the } \\
\text { systematic reviews or meta-analyses that cited the original article. }\end{array}$} \\
\hline & & & \\
\hline \multirow{3}{*}{$\begin{array}{l}\text { Pre- } \\
\text { Registration } \\
(\mathrm{N}=171)\end{array}$} & Statement, says was pre--registered & $8(4.68 \%)$ & $2.29-7.07$ \\
\hline & $\begin{array}{l}\text { Statement, says was not pre- } \\
\text { registered }\end{array}$ & 0 & - \\
\hline & $\begin{array}{l}\text { No, there is no pre-registration } \\
\text { statement }\end{array}$ & $163(95.32 \%)$ & $92.93-97.71$ \\
\hline \multirow{3}{*}{$\begin{array}{l}\text { Test Subjects } \\
(\mathrm{N}=294)\end{array}$} & Animals & $11(3.74 \%)$ & - \\
\hline & Humans & $204(69.39 \%)$ & - \\
\hline & Neither & $79(26.87 \%)$ & - \\
\hline \multirow{7}{*}{$\begin{array}{l}\text { Country of } \\
\text { Journal } \\
\text { Publication } \\
(\mathrm{N}=294)\end{array}$} & US & $182(61.90 \%)$ & - \\
\hline & UK & $34(11.56 \%)$ & - \\
\hline & Germany & $2(0.68 \%)$ & - \\
\hline & India & $11(3.74 \%)$ & - \\
\hline & Italy & $3(1.02 \%)$ & - \\
\hline & Unclear & $9(3.06 \%)$ & - \\
\hline & Other (a) & $53(18.03)$ & - \\
\hline \multirow{5}{*}{$\begin{array}{l}\text { Country of } \\
\text { Corresponding } \\
\text { Author } \\
(\mathrm{N}=294)\end{array}$} & US & $116(39.46 \%)$ & - \\
\hline & China & $20(6.80 \%)$ & - \\
\hline & UK & $14(4.76 \%)$ & - \\
\hline & Germany & $10(3.40 \%)$ & - \\
\hline & Japan & $13(4.42 \%)$ & - \\
\hline
\end{tabular}


bioRxiv preprint doi: https://doi.org/10.1101/773945; this version posted September 25, 2019. The copyright holder for this preprint (which was not certified by peer review) is the author/funder. All rights reserved. No reuse allowed without permission.

\begin{tabular}{|l|l|l|} 
France & $6(2.04 \%)$ & - \\
\hline Canada & $14(4.76 \%)$ & - \\
\hline Italy & $24(8.16 \%)$ & - \\
\hline India & $2(0.68 \%)$ & - \\
\hline Spain & $5(1.70 \%)$ & - \\
\hline Unclear & $11(3.74 \%)$ & - \\
\hline Other & $59(17.69 \%)$ & - \\
\hline
\end{tabular}




\section{Supplemental 2: Additional Characteristics of Reproducibility in Urology Studies}

\begin{tabular}{|c|c|c|}
\hline \multicolumn{2}{|r|}{ Characteristics } & Variables \\
\hline & & $\mathbf{N}(\%)$ \\
\hline \multirow{6}{*}{$\begin{array}{c}\text { Material } \\
\text { Availability } \\
(\mathrm{N}=162)\end{array}$} & Personal or institutional & 0 \\
\hline & $\begin{array}{l}\text { Supplementary information hosted by the } \\
\text { journal }\end{array}$ & 5 \\
\hline & Online third party & 0 \\
\hline & Upon Request & 0 \\
\hline & Yes, material was accessible & 4 \\
\hline & No, material was not accessible & 1 \\
\hline \multirow{9}{*}{$\begin{array}{c}\text { Data } \\
\text { Availability } \\
(\mathrm{N}=171)\end{array}$} & Personal or institutional & 0 \\
\hline & Supplementary journal information & 7 \\
\hline & Online third party & 0 \\
\hline & Upon Request & 0 \\
\hline & Other (b) & 0 \\
\hline & $\begin{array}{l}\text { Yes, data could be accessed and } \\
\text { downloaded }\end{array}$ & 3 \\
\hline & $\begin{array}{l}\text { No, data count not be accessed and } \\
\text { downloaded }\end{array}$ & 4 \\
\hline & Yes, data files were clearly documented & 2 \\
\hline & No, data files were not clearly documented & 1 \\
\hline
\end{tabular}




\begin{tabular}{|c|c|c|}
\hline & Yes, data files contain all raw data & 0 \\
\hline & No, data files do not contain all raw data & 3 \\
\hline & Unclear if all raw data was available & 0 \\
\hline \multirow{7}{*}{$\begin{array}{c}\text { Pre- } \\
\text { Registration } \\
(\mathbf{N}=171)\end{array}$} & Pre-registered on ClinicalTrials.gov & 1 \\
\hline & Other (c) & 7 \\
\hline & Yes, pre-registration was accessible & 4 \\
\hline & $\begin{array}{l}\text { No, pre-registration was not } \\
\text { accessible }\end{array}$ & 4 \\
\hline & Hypothesis was pre-registered & 2 \\
\hline & Methods were pre-registered & 1 \\
\hline & Analysis plan was pre-registered & 0 \\
\hline \multirow{3}{*}{$\begin{array}{l}\text { Protocol } \\
(\mathrm{N}=171)\end{array}$} & Hypotheses was included in the protocol & 0 \\
\hline & Methods were included in the protocol & 0 \\
\hline & Analysis plan was included in the protocol & 0 \\
\hline
\end{tabular}

